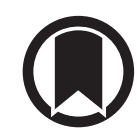

CrossMark

\section{Avoiding ageism and promoting independence from reference equations in lung function testing of older adults}

\author{
To the Editor:
}

We read with great interest the paper on relative and absolute lung function change in a general population aged 62-102 years in the region of Skåne, Sweden [1], since lung function research in the growing age group of older adults, especially those $\geqslant 80$ years old, is indeed limited $[2,3]$.

In the description of spirometry, the authors of that paper state that only one acceptable manoeuvre was required for inclusion to avoid "selection bias among the very old, who may not be able to perform multiple manoeuvres" [1]. The review paper cited by the authors to support this statement refers to a study of 80 participants (75-98 years old) who were current or recent inpatients in rehabilitation wards and referred to as "frail" [4]. While this was clearly not a population-based sample of older adults, even in this small sample of frail older adults, "all patients made at least three attempts, and up to eight attempts were encouraged, if necessary" [4]. Previous research in community-dwelling older adults (including those aged $\geqslant 80$ years) has shown that quality spirometry, including both acceptability and repeatability criteria, can be achieved and should be attempted [5,6]. Even cognitive impairment assessed with a Mini Mental Status Examination may not be a reliable predictor of poor-quality spirometry in very old adults [6]. We think that more details on the quality of spirometry in this large population-based cohort of adults 60100 years old in the region of Skåne would have been helpful for the reader and provided further support against ageism in the application of spirometry. Additionally, a flowchart displaying the attrition of participants through the different spirometry measurements would have made it easier for the reader to follow through and appreciate the representativeness of the study population.

Although not a stated aim of their study, the authors conclude in their discussion that "NHANES III may offer better reference equations for elderly compared to GLI-2012" as in their study "NHANES III z-scores were generally closer to zero compared with GLI-2012 z-scores" [1]. Unfortunately, the discussion paragraph on this topic lacks references to previous published studies. Indeed, a previous European Respiratory Journal article on survival analysis in a Danish sample of adults aged $\geqslant 90$ years has suggested that the third National Health and Nutrition Examination Survey (NHANES III) reference equations might be better than the 2012 Global Lung Function Initiative (GLI-2012) equations, although the C-statistics were very similar and $<0.60$ for both [7]. The comparison between NHANES III and GLI-2012 is problematic first from a methodological aspect as the NHANES III dataset is part of the GLI-2012 dataset, and because both have an age limit (NHANES III, $\leqslant 80$ years; GLI-2012, $\leqslant 95$ years) beyond which extrapolation is applied against the recommendation of international guidelines on spirometry interpretation [8]. While the best approach would be to collect more spirometry data from healthy nonsmokers who are $\geqslant 80$ years old, it is challenging to include a large enough sample of very old adults who are free of any disease that influences lung function, as well as to avoid selection bias by including only the cognitively and physically fittest who participate in research [7]. Hence, there needs to be more consideration of and research on ways to assess lung function without depending on reference equations [9]. Forced expiratory volume in $1 \mathrm{~s}\left(\mathrm{FEV}_{1}\right)$ expressions that are independent of reference values, such as $\mathrm{FEV}_{1} /$ height $^{3}\left(\mathrm{FEV}_{1} / \mathrm{Ht}^{3}\right)$ and $\mathrm{FEV}_{1}$ quotient $\left(\mathrm{FEV}_{1} \mathrm{Q}\right.$ ) (although $\mathrm{FEV}_{1} \mathrm{Q}$ still depends on the externally derived lowest sex-specific percentile, which could differ in different populations [9]), have performed as well as or even better than those dependent on reference values $\left(\mathrm{FEV}_{1}\right.$ percentage of predicted value and $\mathrm{FEV}_{1} \mathrm{z}$-score) in predicting all-cause mortality, first hospitalisation, and physical and cognitive decline in a

@ERSpublications

Spirometry quality and interpretation in very old adults needs to be further researched, especially the use of $\mathrm{FEV}_{1}$ expressions that are independent of reference equations/values http://bit.ly/2R9vyW6

Cite this article as: Hegendörfer E, Degryse J-M. Avoiding ageism and promoting independence from reference equations in lung function testing of older adults. Eur Respir J 2020; 55: 2000033 [https://doi.org/ $10.1183 / 13993003.00033-2020]$. 
cohort of community-dwelling adults aged $\geqslant 80$ years [2]. Short-term relative decline of $\mathrm{FEV}_{1} / \mathrm{Ht}^{3}$ has also been reported to be independently associated with adverse outcomes [3]. We suggest that $\mathrm{FEV}_{1}$ expressions such as $\mathrm{FEV}_{1} / \mathrm{Ht}^{3}$ that are independent of reference values, but still account for some sex and size differences, should be studied in larger cohorts of older adults, and their performance assessed and compared based on their ability to predict relevant adverse outcomes.

Eralda Hegendörfer $\oplus^{1,2}$ and Jean-Marie Degryse $e^{1,2}$

${ }^{1}$ Dept of Public Health and Primary Care, Katholieke Universiteit Leuven (KULeuven), Leuven, Belgium. ${ }^{2}$ Institute of Health and Society, Université Catholique de Louvain (UCLouvain), Brussels, Belgium.

Correspondence: Eralda Hegendörfer, Academic Center for General Practice, Kapucijnenvoer 33 blok j-box 7001, 3000 Leuven, Belgium. E-mail: eralda.turkeshi@kuleuven.be

Received: 8 Jan 2020 | Accepted: 14 Jan 2020

Conflict of interest: None declared.

\section{References}

1 Luoto J, Pihlsgard M, Wollmer P, et al. Relative and absolute lung function change in a general population aged 60-102 years. Eur Respir J 2019; 53: 1701812.

2 Hegendorfer E, Vaes B, Andreeva E, et al. Predictive value of different expressions of forced expiratory volume in 1 second $\left(\mathrm{FEV}_{1}\right)$ for adverse outcomes in a cohort of adults aged 80 and older. J Am Med Dir Assoc 2017; 18: $123-130$.

3 Hegendorfer E, Vaes B, Mathei C, et al. Prognostic value of short-term decline of forced expiratory volume in $1 \mathrm{~s}$ over height cubed $\left(\mathrm{FEV}_{1} / \mathrm{Ht}^{3}\right)$ in a cohort of adults aged 80 and over. Aging Clin Exp Res 2018; 30: 507-516.

4 Allen SC, Yeung P. Inability to draw intersecting pentagons as a predictor of unsatisfactory spirometry technique in elderly hospital inpatients. Age Ageing 2006; 35: 304-306.

5 Haynes JM. Pulmonary function test quality in the elderly: a comparison with younger adults. Respir Care 2014; 59: $16-21$.

6 Turkeshi E, Zelenukha D, Vaes B, et al. Predictors of poor-quality spirometry in two cohorts of older adults in Russia and Belgium: a cross-sectional study. NPJ Prim Care Respir Med 2015; 25: 15048.

7 Miller MR, Thinggaard M, Christensen K, et al. Best lung function equations for the very elderly selected by survival analysis. Eur Respir J 2014; 43: 1338-1346.

8 Pellegrino R, Viegi G, Brusasco V, et al. Interpretative strategies for lung function tests. Eur Respir J 2005; 26: 948-968.

9 Miller MR, Pedersen OF. New concepts for expressing forced expiratory volume in $1 \mathrm{~s}$ arising from survival analysis. Eur Respir J 2010; 35: 873-882.

Copyright @ERS 2020

From the authors:

We thank E. Hegendörfer and J-M. Degryse for their interest and request for clarification regarding the spirometry inclusion criteria of our study as well your suggestions on avenues for future research. As stated in our paper, up to a maximum of eight consecutive breathing manoeuvres were performed with the goal of completing at least three acceptable spirograms [1]. However, there was a minority of subjects who did not manage to perform more than one or two acceptable curves. After closer inspection and communication with the nurses responsible for the spirometries, it became clear that this was mostly an issue for the frail elderly. The reasoning for not discarding these spirometries was that these subjects performed their very best and did produce at least one acceptable curve. Since spirometric data in this age group are very rare, we decided to keep the data and present it to the reader. However, we did not present the proportion of examinations with fewer than three manoeuvres or how these influenced our results. E. Hegendörfer and J-M. Degryse's question is therefore merited.

\section{@ERSpublications}

The proportion of examinations with less than three manoeuvres or how this influenced the results was not presented, so the question is therefore merited. As can be seen, there was little or no difference in outcome. http://bit.ly/2S9XqZe

Cite this article as: Luoto JA, Pihlsgård M. Avoiding ageism and promoting independence from reference equations in lung function testing of older adults. Eur Respir J 2020; 55: 2000172 [https://doi.org/10.1183/ 13993003.00172-2020]. 
TABLE 1 Overview of differences in mean lung volumes depending on inclusion criteria

\begin{tabular}{lcccc} 
Sex & \multicolumn{4}{c}{ FVC all/FVC <3 valid manoeuvres removed $L$} \\
\cline { 2 - 5 } & $\mathbf{6 0 - 6 9}$ years of age & $\mathbf{7 0 - 7 9}$ years of age & $\mathbf{8 0 - 8 9}$ years of age & $\mathbf{9 0 - 1 0 2}$ years of age \\
\hline \multirow{2}{*}{ Male } & $4.13(4.08-4.19) / 4.12$ & $3.60(3.54-3.66) / 3.59$ & $2.97(2.91-3.03) / 2.94$ & $2.62(2.48-2.78) / 2.61$ \\
\multirow{2}{*}{ Female } & $(4.06-4.18)$ & $(3.53-3.65)$ & $(2.89-3.01)$ & $(2.46-2.74)$ \\
& $2.93(2.90-2.97) / 2.93$ & $2.53(2.49-2.57) / 2.51$ & $2.01(1.97-2.04) / 2.01$ & $1.67(1.60-1.73) / 1.68$ \\
& $(2.90-2.97)$ & $(2.47-2.55)$ & $(1.97-2.04)$ & $(1.61-1.74)$ \\
\hline
\end{tabular}

Data are presented as mean (95\% CI). FVC: forced vital capacity.

To illustrate, the proportion of subjects with less than three acceptable manoeuvres was small: for forced vital capacity (FVC), $1.9 \%$ of all subjects had only one acceptable manoeuvre and $2.2 \%$ had two acceptable manoeuvres, while the remaining $96 \%$ had three or more acceptable manoeuvres. To illustrate the impact of inclusion of patients with fewer than three acceptable manoeuvres, we present separate summaries of FVC measurements for all available data and data for which examinations with fewer than three acceptable manoeuvres have been removed (table 1). As you can see, there was little or no difference in outcome.

Finally, we agree that the clinical importance of metrics that do not rely on reference values (e.g. forced expiratory volume in $1 \mathrm{~s}\left(\mathrm{FEV}_{1}\right)$ expressions such as $\mathrm{FEV}_{1} /$ height ${ }^{3}$ or even Emphysema Severity Index [2]) should be evaluated in large, population-based cohorts that include the very old.

Johannes A. Luoto (ib) and Mats Pihlsgård

Dept of Clinical Sciences in Malmö, Division of Geriatric Medicine, Lund University, Malmö, Sweden.

Correspondence: Johannes A. Luoto, Dept of Clinical Sciences in Malmö, Division of Geriatric Medicine, Jan Waldenströms gata 35, SE-205 02, Malmö, Sweden. E-mail: johannes.luoto@med.lu.se

Received: 27 Jan 2020 | Accepted: 28 Jan 2020

Conflict of interest: J.A. Luoto reports grants from Skåne County, during the conduct of the study. M. Pihlsgård has nothing to disclose.

\section{References}

1 Luoto J, Pihlsgård $\mathrm{M}$, Wollmer $\mathrm{P}$, et al. Relative and absolute lung function change in a general population aged 60-102 years. Eur Respir J 2018; 53: 1701812.

2 Occhipinti M, Paoletti M, Bartholmai BJ, et al. Spirometric assessment of emphysema presence and severity as measured by quantitative CT and CT-based radiomics in COPD. Respir Res 2019; 20: 101. 